\title{
Konsep Kepemimpinan Raden Mas Sahid Dan Aplikasinya Di Zaman Modern
}

\author{
Bani Sudardi \\ Universitas Sebelas Maret \\ banisudardi@yahoo.co.id
}

\section{Article History}

received 1/9/2021

revised $1 / 10 / 2021$

accepted 1/11/2021

\begin{abstract}
The prince of Mas Sahid or Mangkunegara I is a figure who has an extraordinary leadership spirit so as to be able to establish mangkunegaran work with a strong army. The paper of this study seeks to understand the concept of mangkunegaran. The paper of this study used literature review method. The emergence of mangkunegaran legions comes from the struggle of The prince of Mas Said along with his followers who feel disillusioned with the government and then injustice done by Paku Buwono II. The embryos of the mangkunegaran legion are soldiers eho fought together with The prince of Mas Said. With "ikrar tiji tibeh" which means if one of the fallen all feel, when one gets happiness then all participate in enjoying it, the way it the purpose of The prince of Mas Said to unite his legions and getting win in the warious battles. In his struggle, The prince Mas Said cooperates with Sunan Kuning and the prince of Mangkubumi. When working with Sunan Kuning, The prince of Mas Sahid is equipped with the ability to set strategies and how to use weapons and then then appointed as a "senopati" with the title of prince of prangwedanan who led 300 death squads of soldiers. The first battle with Sunan Kuning was against the soldiers of Kompeni and soldiers of Ternate and then the prince of Mas Said is winner. After conquering Madiun and Ponorogo, the prince of Mas Said dissever with Sunan Kuning, the prince of Mas Said was later caught and wxiled to Sri Langka. The paper is attempts to reveal the concept of leadership of the prince of Mas Said that managed to win various wars and then united the troops.
\end{abstract}

Keywords: mangkunegaran, leadership, modern era

\begin{abstract}
Abstrak
Raden Mas Sahid atau yang kemudian menjadi Mangkunegara I adalah seorang tokoh yang memiliki jiwa kepemimpinan yang luar biasa sehingga mampu mendirikan Kerajaan Mangkunegaran dengan pasukan kuat. Paper ini berusaha memahami konsep kepemimpinan Mangkunegaran. Metode yang ditempuh adalah metode kajian pustaka. Munculnya Legiun Mangkunegaran berawal dari perjuangan Raden Mas Said bersama para pengikutnya yang merasa kecewa terhadap pemerintahan serta ketidakadilan yang dilakukan oleh Paku Buwono II. Embrio dari Legiun Mangkunegaran adalah prajurit yang berjuang bersama Raden Mas Said. Dengan ikrar tiji tibeh yang artinya apabila salah satu ada yang jatuh semua ikut merasakan, apabila salah satu mendapat kebahagiaan maka semua ikut menikmati, Raden Mas Said dapat menyatukan pasukannya dan memenangkan berbagai pertempuran. Dalam perjuangannya, Raden Mas Said melakukan kerjasama dengan Sunan Kuning dan Pangeran Mangkubumi. Ketika bekerjasama dengan Sunan Kuning, Raden Mas Said dibekali dengan kepandaian mengatur strategi serta cara menggunakan senjata dan kemudian diangkat sebagai senopati yang bergelar Pangeran Prangwedana memimpin 300 orang prajurit berani mati. Pertempuran pertama yang dilakukan bersama Sunan Kuning adalah melawan prajurit \pm prajurit Kompeni dan prajurit dari Ternate dan Raden Mas Said memperoleh kemenangan. Setelah menaklukkan Madiun dan Ponorogo, Raden Mas Said berpisah dengan Sunan Kuning yang kemudian tertangkap dan di buang ke Sri Langka. Artikel ini mencoba mengangkap konsep kepemimpinan Raden Mas Sahid yang berhasil memenangkan berbagai peperangan dan mempersatukan pasukan.
\end{abstract}

Kata kunci: Mangkunegaran, kepemimpinan, zaman modern

Social, Humanities, and Education Studies (SHEs): Conference Series

p-ISSN 2620-9284

https://jurnal.uns.ac.id/shes

e-ISSN 2620-9292

This work is licensed under a Creative Commons Attribution-ShareAlike 4.0

International License. 


\section{PENDAHULUAN}

Pangeran Sambernyawa lahir dengan nama Raden Mas Said. Beliau lahir di kraton Kartasura pada 7 April 1725 M. Ayahnya, Kanjeng Gusti Pangeran Haryo Mangkoenegara Kartasuro atau Mangkunegara Sepuh, adalah putra tertua Amangkurat Jawi yang sempat menjadi kandidat calon raja. Pada awal perjuangannya, Pangeran Sambernyawa meninggalkan Kraton Kartasura dan melakukan pertempuran yang membutuhkan waktu 16 tahun lamanya. Pertempuran berlangsung pada tahun 1740-1757 M dan dibagi menjadi tiga periode atau tiga bagian. Bagian pertama adalah ketika Pangeran Sambernyawa Sambernyawa bergabung dengan pasukan Sunan Kuning di Randulawang pada tahun 1741-1742 M, bagian kedua pada masa Pangeran Sambernyawa bergabung dengan Pangeran Mangkubumi pada tahun 1743-1752 M, bagian ketiga ketika Pangeran Sambernyawa melawan Belanda (VOC), Sultan Hamengkubuwono I dan Susuhan Pakubuwono III pada tahun 1752-1757 M. (Hendrawan, 2020).

Dalam perjuangannya, Raden Mas Said melakukan kerjasama dengan Sunan Kuning dan Pangeran Mangkubumi. Ketika bekerjasama dengan Sunan Kuning, Raden Mas Said dibekali dengan kepandaian mengatur strategi serta cara menggunakan senjata dan kemudian diangkat sebagai senopati yang bergelar Pangeran Prangwedana memimpin 300 orang prajurit berani mati (Sudijono, 2010). Pertempuran pertama yang dilakukan bersama Sunan Kuning adalah melawan prajurit-prajurit Kompeni dan prajurit dari Ternate dan Raden Mas Said memperoleh kemenangan. Setelah menaklukkan Madiun dan Ponorogo, Raden Mas Said berpisah dengan Sunan Kuning . Mereka berjuang sendiri-sendiri. Sunan Kuning sendiri kemudian tertangkap Belanda dan di buang ke Ceylon (Pratiwi, Anita Dian Joebagyo, Hermanu Yunianto, 2019)

Raden Mas Said kemudian melanjutkan perjuangannya sendiri. Paku Buwana meminta Pangeran Mangkubumi untuk mengalahkan Raden Mas Said dengan janji diberikan Tanah Sukawati. Pangeran Mangkubumi kemudian melarikan diri dari kraton dan melawan Susuhunan Pakubuwana.

Pangeran Mangkubumi kemudian bergabung dengan Raden Mas Said. Dia mengangkat Raden Mas Said sebagai menantu sekaligus. Kerjasama dengan Pangeran Mangkubumi dilatarbelakangi adanya kekecewaan dari Pangeran Mangkubumi terhadap Paku Buwono II. Sebelumnya, Paku Buwono II menjanjikan hadiah tanah lungguh sebesar 3.000 cacah kepada siapa saja yang berhasil mengalahkan Raden Mas Said (Wasino, 2014). Ketika Pangeran Mangkubumi berhasil mengalahkan Raden Mas Said dan menuntut hadiah tanah lungguh yang telah dijanjikan, Paku Buwono II tidak memenuhi janjinya dan Pangeran Mangkubumi keluar dari Keraton bergabung dengan Raden Mas Said untuk melakukan perlawanan.

Kerjasama Raden Mas Said dengan Pangeran Mangkubumi tidak berjalan lama, karena Pangeran Mangkubumi menghendaki perdamaian dengan Belanda. Kemudian pada tahun 1755 terjadi perjanjian Giyanti yang membagi Mataram menjadi dua bagian (Pratiwi, Anita Dian Joebagyo, Hermanu Yunianto, 2019). Wilayah tersebut ialah Kasunanan Surakarta dengan raja Pakubuwana dan Kasultanan Yogyakarta dengan raja Pangeran Mangkubumi yang bergelar Sri Sultan Hamengkubuwana I.

\section{METODE}

Metode yang digunakan dalam kajian ini ialah metode kualitatif deskriptif. Dalam analisis digunakan metode kritis, yakni dengan cara mengkritisi berbagai temuan-temuan yang yang diperoleh. Sumber data utama penelitian ini ialah berupa bahan-bahan singgah kajiannya dipusatkan pada konten analisis. Analisis digunakan dengan menggunakan teknik analisis interaktif, yakni dengan cara menganalisis data sambil melakukan penarikan kesimpulan.

Data penelitian ini adalah berbagai informasi tentang Raden Mas Said dan perjuangannya di dalam melawan Belanda dan pasukan kasunanan Surakarta. Data-data dapat berupa cerita rakyat, dokumen tertulis, dan sebagainya. Sementara itu sumber data utama adalah dokumen dokumen tertulis mengingat bahwa peristiwa dan informan mengenai hal terkait dengan subjek kajian sudah tidak dapat ditemukan.

\section{HASIL DAN PEMBAHASAN}

Perjuangan Raden Mas Said erat kaitannya dengan sejarah berdirinya Kabupaten Wonogiri. Perjuangan ini dimulai dusun Nglaroh, Desa Pule Kecamatan Selogiri. Di daerah inilah dimulainya 
penyusunan bentuk organisasi pemerintahan yang masih sangat terbatas dan sangat sederhana, yang dikemudian hari menjadi simbol semangat pemersatu perjuangan rakyat. Inisiatif untuk menjadikan Nglaroh sebagai basis perjuangan pangeran Sambernyawa, adalah dari rakyat Wonogiri sendiri (Wiradiwangsa). Tepatnya pada hari Rabu Kliwon tanggal 3 Rabi'ul awal (Mulud) Tahun Jumakir, Windu Senggoro : Angrasa retu ngoyag jagad yang bermakna karena merasa tidak enak, maka digoyangah dunia. Kalimat ini merupakan kaliman yang membentuk angkata tahu Jawa yang bertepatan dengan tanggal 17 Mei 1741 (Astuti, 2012).

Perjuangan Raden Mas Said dalam melawan kasunanan dan pemerintahan Belanda menggunakan konsep yang disebut sebagai Tridharma. Konsep Tridharma ini merupakan konsep awal sebagai bekal dalam melawan kesewenang-wenangan. Konsep tersebut terdiri dari 3 kalimat sebagai berikut.

1. Rumangsa melu handarbeni (merasa ikut memiliki)

2. Wajib melu hangrungkebi (wajib untuk membela)

3. Mulat sarira hangrasa wani (instrukspeksi diri dan timbulaah keberanian).

Konsep Tri Dharma tersebut menjadi modal dasar dalam perjuangan. Perjuangan Raden Mas Said adalah perjuangan yang bersifat lokal, namun implikasi dari perjuangan tersebut dapat diperluas kepada perjuangan nasional. Konsep Tridharma ini tidak lepas dari kenyataan yang dialami oleh raden Mas Said yaitu itu bawa dia merasa memiliki kerajaan Mataram karena ayahnya sebenarnya termasuk keluarga raja yang memiliki kesempatan untuk duduk sebagai pimpinan.

Karena melihat kondisi kerajaan Mataram yang kurang baik dan sangat dipengaruhi oleh kolonial Belanda, maka Raden Mas Said merasa bahwa dia harus ikut membela kerajaan Mataram tersebut dan membersihkan dari hal-hal yang tidak semestinya. Karena itu Raden Mas Said kemudian melakukan instrospeksi dan dalam instruksi itu Dia merasa bahwa wa dia harus berani untuk melakukan suatu tindakan yang kemudian diwujudkan dengan cara mengangkat senjata melawan susuhunan yang dibela oleh kompeni Belanda. Inilah latar belakang sejarah tentang konsep Tri Dharma yang yang dianut oleh raden Mas Said.

Konsep Tridharma ini kemudian dimanifestasikan dalam gerakan yaitu gerakan untuk menegakkan kerajaan Mataram. Beberapa tindakan Raden Mas Said untuk mengimplementasikan tridharma tersebut dilakukan dengan cara cara sebagai berikut.

1. Raden Mas Said melarikan diri ke dusun Nglaroh Desa Pule. Kecamatan Selogiri. Di daerah inilah dimulainya penyusunan bentuk organisasi pemerintahan yang masih sangat terbatas dan sangat sederhana, yang dikemudian hari menjadi simbol semangat pemersatu perjuangan rakyat. Pangeran Sambernyawa memotivasi rakyat rakyat dengan semboyan "Tiji tibeh, Mati Siji Mati Kabeh, Mukti Siji Mukti Kabeh" (Astuti, 2012).

2. Konsep tiji tibeh ini konsep untuk membangun kebersamaan dalam masing-masing unsur agar tidak timbul rasa cemburu. Konsep ini dapat dimaknai bahwa apabila cita-cita Raden Mas Said bersama rakyat dalam memperjuangkan memperjuangkan cita-cita harus didasari pada rasa yang sama atau solidaritas bahwa bila cita-cita itu tercapai maka setiap anggotanya akan mendapatkan bagian kemuliaan.

3. Raden Mas Syahid bergabung dengan Sunan Kuning untuk melakukan peperangan melawan kompeni dan kasunanan yang dianggapnya telah merusak keadaan dan peraturan kerajaan Mataram.

4. Raden Mas Syahid bergabung dengan Pangeran Mangkubumi untuk membangun kekuatan yang lebih kuat dalam mengalahkan company dan kasunanan. Meskipun perjuangan ini tidak berlangsung lama, tetapi telah menjadikan Kompeni nya dan kasunanan merasa kewalahan menghadapi keduanya.

Secara ringkas Perjuangan Raden Mas Said dapat dijabarklan sebagai beriku. Raden Mas Garendi, juga disebut Sunan Kuning, yaitu seorang cucu raja Amangkurat III dari Mataram. Tahun 1742, ketika dia berumur 12 tahun, dia dinaikkan sebagai raja Mataram oleh pemberontak yang menantang kekuasaan Susuhunan Pakubuwana II (bertahta bertahta 1729-1746). Raden Mas Said dilahirkan di Keraton Kartasura pada 17 April 1725. Ayahnya bernama Kangjeng Pangeran Arya Mangkoenagoro dan ibunya Raden Ayu Wulan, puteri dari pangeran Balitar. Ayahnya dikenal sebagai pangeran yang cerdik berkat ilmunya yang mendalam tentang sastra dan tradisi Jawa. Itulah karenanya dia dianggap pantas menggantikan tahta ayahnya yaitu Amangkurat IV. Namun 
suasana politik keraton Kartasura tidak terlalu nyaman untuk sang pangeran. Semenjak adindanya naik tahta dengan gelar Pakubuwana II, dia malahan dianggap duri dalam daging untuk klik kerajaan yaitui bunda raja, Gusti Kangjeng Ratu Ageng dan Patih Danureja. Dia pun difitnah dan belakangnya dibuang ke Ceylon sampai ke Kaapstad.

Semenjak pembuangan ayahnya Raden Mas Said dan adindanya Raden Mas Ambia danRaden Mas Sabar hidup menyedihkan. Mereka sebelumnya juga telah dilepas ibunya. Ketiga anak itu hidup dalam suasana kemelaratan dan tersisih dari kehidupan istana. Tidak benar lagi pada mereka terpancar gambaran sebagai putera yang dipersiapkan menjadi raja. Namun pada sisi lain menempuh kehidupan yang penuh penderitaan ini dia sangat dekat dengan rakyat kecil. Kenalan dekat mereka yang selalu menemani yaitu Raden Sutawijaya dan Raden Suradiwangsa

Menjelang usia 14 tahun oleh Pakubuwana II, Raden Mas Said dinaikkan menjadi seorang Manteri Gandek dengan gelar Raden Mas Ngabehi Suryakusuma dengan mendapat tanah lungguh( jabatan) seluas 50 karya. Ketika terjadi pelarian orang-orang Cina dari Batavia meluas ke Kartasura pada 1740 sempat timbul perlawanan rakyat untuk penguasa VOC di Kartasura. Atas huru-hara ini Raden Mas Said bersimpati pada perlawanan rakyat. Pasukan pemberontakan yang dipimpin oleh Mas Garendi sukses merebut keraton.

Kondisi keraton yang kurang terlindung dan kekhawatiran hendak keselamatan adik-adiknya, Raden Mas Said memutuskan untuk meninggalkan istana disertai oleh teman-temannya seperti Sutawijaya dan Suradiwangsa. Atas saran Suradiwangsa Raden Mas Said dianjurkan untuk pergi ke Nglaroh, kawasan tempat Suradiwangsa pada 1741. Selama di Nglaroh Raden Mas Said bersama adik-adiknya dan pengikutnya melaksanakan latihan perang sebagai persiapan melawan Belanda. Di Nglarohlah kharisma Raden Mas Said mulai bersinar. Dia tumbuh menjadi pimpinan perjuangan melawan Belanda. Sebagai pimpinan perjuangan dia mengangkat Raden Sutawijaya sebagai panglima perang dan diberi gelar Raden Ngabehi Rangga Panambang. Sementara Suradiwangsa dinaikkan sebagai patih dan diberi gelar Kyai Kudanawarsa.

Semenjak 1741 Raden Mas Said mengobarkan perlawanan terhadap Belanda selama 16 tahun. Periode perang pertama (1741-1742) bergabung dengan Sunan Kuning di Randu Lawang. Periode kedua selama sembilan tahun (1743-1752) bersama dengan Pangeran Mangkubumi. Periode ketiga selama lima tahun (1752-1757) Raden Mas Said berjuang sendiri melawan VOC, Sultan Hamengku Buwana I danPakubuwana III. Selama perjuangannya yang sangat panjang, berpindah-pindah ajang pertempuran, dan melelahkan itu Raden Mas Said selalu ditemani oleh neneknya Raden Ajeng Sumanarsa, kedua isterinya (Kangjeng Ratu Bendara dan Mas Ayu Matah Ati), putera-puteranya serta pengikut setianya. Mereka semua terlatih duduk di atas punggung kuda, naik-turun pegunungan dan lembah, serta berbakat dalam bertahan hidup. Kesatuan mereka yang selalu sukses dikawal karena semangat TIJI-TIBEH. Keteguhan Raden Mas Said dalam berjuang belakangnya sukses memaksakan janji politik dengan Pakubuwana III di Salatiga yang mendasari berdirinya pemerintahan Mangkunegaran (Noname, 2021).

\section{Konsep Kepemimpionan Raden Mas Said}

Berikut ini disajikan tentang konsep kepemimpinan yang dimunculkan oleh Raden Mas Said dalam perjuanganya.

1. Konsep solidaritas merupakan hal yang sangat mendasar dalam kepemimpinan Raden Mas Said. Dalam solidaritas tersebut digambarkan sampai kepada hal yang sangat sensitif ialah kematian seperti digambarkan tiji tibeh, yakni bila Mati satu maka mati semuanya.

2. Yang selanjutnya juga digambarkan tentang konsep keadilan yaitu apabila dalam perjuangan tersebut mendapatkan hasil, maka Hasil tersebut dinikmati bersama yang dinyatakan dengan mukti siji Mukti kabeh. Konsep ini sangat penting dalam membangun solidaritas sehingga rakyat merasa tidak hanya sebagai alat, melainkan juga diajak bersama-sama cita-cita.

3. Konsep selanjutnya ialah adanya satu slogan untuk membangun cita-cita dan menjalankan kepemimpinan tersebut, slogan tersebut ialah yang menjadi tujuan dan citacita dalam melakukan perjuangan. Artinya, perjuangan tersebut bukan hanya untuk mencari sesuatu yang tidak jelas, melainkan memperjuangkan sesuatu yang dianggap 
baik dan mulia. Perjuangan tersebut akan mengangkat semua anggota atau semua peserta dalam keadaan yang lebih baik.

Konsep kepemimpinan Raden Mas Said ini kemudian dikaitkan peristiwa-peristiwa yang tercatat di dalam babad atau menjadi cerita rakyat. Dalam kepemimpinan, Raden Mas Sahid mengenal betul pengikutnya sehingga ia membagi pengikutnya dalam beberapa jenis (Astuti, 2012) yang dapat disajikan dalam bentuk tabel berikut.

\begin{tabular}{|c|c|c|c|}
\hline No & Lokasi & Sebutan & Arti \\
\hline 1 & $\begin{array}{l}\text { Wilayah Nglaroh dan } \\
\text { sekitarnya }\end{array}$ & $\begin{array}{l}\text { Bandol } \\
\text { ngompol }\end{array}$ & Suka berkumpul, kuat jasmani rohani \\
\hline 2 & $\begin{array}{l}\text { Sembuyan, } \\
\text { Wuryatoro }\end{array}$ & $\begin{array}{l}\text { Kutuk kalung } \\
\text { klendho }\end{array}$ & $\begin{array}{l}\text { Penurut, mudah diperintah, } \\
\text { paternalistik }\end{array}$ \\
\hline 3 & Saroko (Tirtomoyo) & $\begin{array}{l}\text { Kethek } \\
\text { saranggon }\end{array}$ & $\begin{array}{l}\text { Suka bergerombol, sulit diatur, mudah } \\
\text { tersinggung }\end{array}$ \\
\hline 4 & Keduwang & $\begin{array}{l}\text { Lemah bang } \\
\text { gineblekan }\end{array}$ & $\begin{array}{l}\text { Suka berfoya-foya dan sulit diatur, } \\
\text { namun bila pandai mengambil hati } \\
\text { akan jadi berguna }\end{array}$ \\
\hline 5 & Honggobawayan & $\begin{array}{l}\text { Asu galak } \\
\text { ora nyathek }\end{array}$ & $\begin{array}{l}\text { Orangnya kelihatannya ganas dan } \\
\text { susah diatur, tetapi tidak berbahaya. }\end{array}$ \\
\hline
\end{tabular}

Kepemimpinan Raden Mas Said juga diwujudkan dalam bentuk profesionalisme. Di dalam memimpin peperangan raden Mas Syahid banyak melakukan latihan-latihan dan teknik berperang seperti berpura-pura gila atau jejemblungan (untuk mengelabui musuh), perang gerilya (dhedhemitan), dan berusaha untuk tidak dapat ditangkap musuh (weweludan).

Profesionalisme tersebut tidak hanya ditunjukkan melalui keterampilan-keterampilan jasmani, melainkan juga dilakukan dengan menggunakan keterampilan rohani yakni penggemblengan rohani sehingga mempunyai jiwa yang kuat dan tahan banting. Karena ini, dalam cerita rakyat tentang perjuangan Raden Mas Said itu ditemukan tempat-tempat yang penggemblengan minta spiritual. Sebagai contoh terdapat suatu Sendang yang disebut sebagai Sendang Siwani yang berarti Sendang yang yang pemberani. Disebut demikian karena di dalam perjuangan Raden Mas Said Sendang tersebut dipercaya dapat membangkitkan keberanian karena simbol keyakinan akan mendapatkan kemenangan. Sendang siwani tersebut diilhami oleh sebuah cerita tentang seekor kebo dugul atau tidak bertanduk yang mati-matian kerbau bule yang besar dan kuat. Namun demikian, kerbau tersebut bisa menang menghadapi kerbau bule yang kuat tersebut karena meminum air Sendang Siwani. Cerita tersebut sebenarnya merupakan bentuk simbolisme, kerbau dugul adalah simbol dari rakyat jelata yang tidak memiliki kekuatan sementara kerbau bule yang besar dan memiliki tanduk lebar adalah simbol dari pemerintah Belanda yang kuat. Namun Raden Mas Said berhasil meyakinkan bahwa penduduk Jawa memiliki kekuatan yang dapat mengalahkan orang-orang Belanda.

Cerita tentang Raden Mas Said yang yang melarikan diri dan menyeberangi Sungai Bengawan Solo menunjukkan jiwa keperkasaan beliau bahwa sebagai pemimpin beliau akan menjadi orang yang terakhir dalam usaha menyelamatkan diri. Hal ini menunjukkan bahwa beliau tidaklah mementingkan dirinya sendiri tetapi lebih mengutamakan kepada para pengikutnya. Konsep ini tampak dari sebuah folklor yang disebut sebagai folklor lisan Nambangan sebagai berikut.

Kepergian pangeran Sambernyawa meninggalkan Kartasura ternyata terus dipantau Belanda dan Paku Buwono II, sehingga terus berusaha mengikutinya. Untuk dapat masuk wilayah desa Pule yang akan dijadikan markas, Pangeran Sambernyawa harus menyeberangi sungai bengawan Solo. Di tepi sungai Bengawan Solo Pangeran Sambernyawa ditolong oleh seorang panambang dengan mengunakan gethek (sampan dari bambu), setelah semua rombongan diseberangkan maka hanya tinggal pangeran Sambernyawa, oleh si panambang yang bernama Joselesono pangeran Sambernyawa di seberangkan tidak mengunakan gethek melainkan dengan menggunakan selembar daun lumbu dengan tujuan agar gethek tetap tertambat dalam keadaan kering untuk mengecoh Belanda seolah-olah tidak ada bekas orang menyeberang. Dan ternyata 
benar setelah Joselesono kembali kearah utara sungai bengawan Solo datanglah pasukan Belanda melacak perjalanan Pangeran Sambernyawa, atas kepandaian tukang panambang akhirnya tidak terlacak (Astuti, 2012).

Kepemimpinan Raden Mas Said merupakan ke kemimpinan yang memiliki ciri kepemimpinan Jawa yang diwarisi dari leluhur mereka yang tergambar dalam serat Babad Tanah Jawi. Dalam serat babad Tanah Jawi digambarkan bahwa logika spiritual para raja-raja tidak terlepas dari kepercayaan kepada hal-hal gaib ((Aryanto et al., 2019). Tampaknya raden Mas Said mewarisi konsep perjuangan Sultan Agung yang merupakan raja ke-3 dari kerajaan Mataram.

Kerajaan Mataram sendiri sebenarnya juga mewarisi konsep-konsep kepemimpinan dari Demak dan Pajang. Kerajaan Pajang merupakan Penerus Kesultanan Demak.Legitimasi atas sebagai Penerus diperoleh melalui politik dan keturunan, sebagai keturunan Majapahit serta sebagai menantu Sultan Trenggono, Sultan terakhir Demak.Transisi dari Demak ke Pajang merupakan konflik berdarah yang memakan banyak korban.Perang Suksesi tersebut diakhiri oleh pertarungan antara Jaka Tingkir dan Arya Panangsang. Jaka Tingkir berhasil mengalahkan Arya Penangsang, sehingga Demak Jatuh ke tangan Jaka Tingkir dan kemudian ia memindahkan wilayah kekuasaannyake Pajang. Yang mengalahkan Arya Penangsang adalah Panembahan Senopati yang merupaka suruhan Sultan Pajang tersebut. Panembahan Senapati sendiri kemudian merupakan pendiri kerajaan Mataram (Maulana, 2015).

Raden Mas Said juga sangat memperhatikan rakyatnya karena dia mewarisi konsep dari Sultan Pajang. Hadiwijaya sebagai Sultan Pajang mencohkan politik terbuka dan berpesan agar seluruh keturunanya bisa tetap menghormati saudara tuanya. Untuk meningkatkan kesejahteraan masyarakat pemerintah mengembangkan beberapa tempat sarana prasarana, seperti pasar sebagai sarana untuk masyarakat. Bandar-bandar untuk memudahkan dalam mengangkut barang yang akan di distribusikan ke wilayah mancanegara. Adanya bandar-bandar tersebut jalur lalu lintas pada masa kerajan Pajang sangat ramai (Muthi"ah, 2019).

Saatnya kita membahas tentang nilai-nilai pimpinan Raden Mas Said untuk diterapkan dalam zaman modern ini. Tentu saja nilai-nilai tidak dapat secara cara tepat diterapkan di zaman modern ini karena kondisi sosial, politik, lingkungan yang berbeda. Namun demikian, nilai-nilai tetap dapat diterapkan dengan suatu penyesuaian. Hakekatnya kita adalah menggali nilai-nilai kearifan lokal yang telah dibangun oleh pendahulu kita.

Nilai kearifan lokal berhubungan dengan kepemimpinan Raden Mas Said yang pertamatama perlunya suatu slogan, atau visi-misi di dalam mengejar suatu cita-cita. Tanpa suatu visi misi slogan atau cita-cita, maka usaha-usaha yang tidak dapat ditentukan arahnya dan tidak dapat diukur. Nilai kearifan lokal berhubungan dengan kepemimpinan Raden Mas Said yang pertamatama perlunya suatu slogan, atau visi-misi di dalam mengejar suatu cita-cita. Tanpa suatu visi misi slogan atau cita-cita, maka usaha-usaha yang tidak dapat ditentukan arahnya dan tidak dapat diukur.

Visi misi yang baik memberikan batasan-batasan pembuatan kebijakan mengenai apa yang dapat dan tidak dapat ditempuh oleh para pemimpin organisasi. Dengan demikian kesalahan membuat kebijakan yang tidak sesuai dengan tujuan organisasi akan jauh berkurang. Visi misi yang baik akan memberikan makna terhadap apa yang dilakukan oleh orang-orang dalam organisasi. Sebagaimana diketahui manusia yang menggerakkan organisasi pada dasarnya bukan mesin. Mereka dapat bekerja sepenuh hati jika memahami apa makna tindakan-tindakan itu bagi organisasi dan bagi keyakinan-keyakinan mereka sendiri. Visi yang baik memberikan makna terhadap setiap tindakan yang mereka lakukan (Hamdan, 2001).

Kepemimpinan Raden Mas Said mengedepankan suatu aspek yaitu solidaritasSolidaritas merupakan sesuatu yang sangat penting dalam kepemimpinan komunal. Konsep tiji tibeh adalah suatu konsep Solidaritas yang menjanjikan mendapatkan bagian yang memadai dari hasil perjuangan, sekaligus harus memiliki tanggung jawab dalam perjuangan itu sampai pada risiko kematian. Solidaritas merupakan konsep kepemimpinan yang sangat penting di dalam setiap organisasi apapun.

Kepemimpinan Raden Mas Said mengedepankan suatu aspek yaitu solidaritas. Solidaritas adalah keadaan saling percaya antara para anggota dalam suatu kelompok atau komunitas. Kalau orang saling percaya mereka akan menjadi satu/menjadi persahabatan, menjadi saling hormat menghormati, menjadi terdorong untuk bertanggung jawab dan memperhatikan kepentingan 
bersama. Konsep inilah yang dibangun oleh Raden Mas Said sehingga dia memiliki pasukan yang tangguh dan tidak berkhianat (Saidang \& Suparman, 2019).

Seorang pemimpin perlu memahami karakter orang yang dipimpin sehingga dapat mengarahkan orang yang dipimpin itu sesuai dengan kondisinya. Raden Mas Said kiranya mengenal betul orang-orang yang dipimpinnya. Penyebutan jenis-jenis karakter rakyat dengan berbagai terminologi menunjukkan bahwa karakter tersebut sangat penting untuk diketahui di dalam menentukan perjuangannya. Di zaman modern ini, memahami karakter orang yang dipimpinnya adalah sangat penting dalam rangka mengarahkan menuju kepada suatu tujuan yang sudah ditentukan dalam visi misi. Dengan mengetahui karakter orang yang dipimpinnya, seorang pemimpin dapat memprediksi hasil yang akan diperolehnya. Dalam konsep kepemimpinan Indonesia, dapat dikembangkan dengan memahami karakter suku bangsa suku bangsa yang ada di Indonesia. Sebagaimana kita ketahui bahwa setiap suku bangsa memiliki karakter karakter dan tradisi budaya yang berlain-lainan. Sebagai contoh, orang Madura memiliki tradisi yang disebut carok yang merupakan sebuah tradisi untuk menutupi rasa malu. Karena itu dalam kebudayaan Madura rasa malu merupakan suatu hal yang perlu dihindari dalam kehidupannya bahkan akan ditebus dengan kematian dengan cara pertarungan dengan menggunakan celurit yang disebut carok apabila sampai terjadi rasa malu dalam kehidupannya.

Konsep kepemimpinan Raden Mas Said selanjutnya ialah keterlibatan langsung di dalam perjuangannya. Konsep ini adalah suatu konsep yang mendekatkan diri kepada rakyatnya sehingga timbul suatu simpati. Dalam kebudayaan Jawa, kebersatuan antara pimpinan dan yang dipimpin adalah sesuatu yang sangat penting. Hal ini disimbolkan sebagai"manunggaling kawula Gusti". Terminologi ini adalah suatu terminologi untuk menggambarkan hubungan manusia dengan Tuhan sekaligus juga untuk menggambarkan hubungan Raja dengan rakyatnya. Konsep seperti ini merupakan satu konsep yang harus diterapkan dalam kepemimpinan modern ini agar setiap pemimpin merasakan suatu dinamika yang terjadi didalam rakyatnya serta aspirasi-aspirasi yang dalamnya.

Ciri kepemimpinan Raden Mas Said yang lain ialah selalu mendekatkan diri kepada Tuhan Yang Maha Esa. Konsep mendekatkan diri kepada Tuhan Yang Maha Esa merupakan ciri khas kepemimpinan indonesia yang sudah seharusnya setiap pemimpin memiliki keyakinan yang Teguh kepada Tuhan Yang Maha Esa. Di era modern ini perlu kiranya menerapkan professionalism yang baik, tetapi juga tidak meninggalkan keyakinan kepada Tuhan Yang Maha Esa sesuai dengan agama dan kepercayaannya.

Konsep yang terakhir adalah konsep yang selalu memberi perhatian kepada rakyat. Seorang pemimpin kecil apapun, harus terlalu memberi perhatian kepada bawahannya. Raden Mas Said di dalam memimpin rakyatnya suka memberikan hadiah-hadiah sesuai dengan jasa yang telah diberikan. Usaha seperti itu sangat penting di zaman modern ini, karena kepemimpinan yang baik adalah kepemimpinan yang dapat memberikan rasa aman dan penghargaan terhadap prestasi prestasi yang dihasilkan. Terdapat konsep punish and reward, namun konsep tersebut bukan didasarkan atau ditekankan pada konsep menghukum namun lebih dikembangkan pada konsep untuk memberi penghargaan, apresiasi, menghargai prestasi.

\section{SIMPULAN}

Berdasarkan uraian yang sudah dilakukan, maka dapat diambil Suatu kesimpulan bahwa Raden Mas Said adalah seorang pejuang yang memiliki konsep-konsep kepemimpinan yang baik. Konsep tersebut adalah satu konsep yang diwarisi dari pendahulu pendahulu mereka. Raden Mas Syahid menciptakan sendiri slogan-slogan untuk membangun kebersamaan sehingga sebagai pemimpin perjuangan beliau dapat bertahan sampai dicapainya suatu perjanjian yang mendudukkannya sebagai seorang pimpinan di dalam pura Mangkunegaran.

Dengan suatu adaptasi konsep kepemimpinan Raden Mas Said tersebut dapat diterapkan dalam kepemimpinan di zaman modern ini. Konsep kepemimpinan tersebut adalah 1 konsep yang universal, namun didalamnya juga terdapat kearifan lokal kearifan lokal yang merupakan ciri khas kepemimpinan Jawa.

\section{DAFTAR PUSTAKA}


Aryanto, A., Sudardi, B., Purwasito, A., \& Rais, W. A. (2019). Spiritual Logic as Culture and Political Expression in Sultan AgungHanyakrakusuma's Ruling. 279 (Icalc 2018), 147-152. https://doi.org/10.2991/icalc-18.2019.21

Astuti, D. (2012). FOLKLOR SAMBERNYAWA DI WONOGIRI SEBAGAI MATERI PEMBELAJARAN SEJARAH (Studi Kasus di SMA Negeri I Girimarto Wonogiri) (Thesis). Tersedia dari Pascasarjana, Universitas Sebelas Maret.

Hamdan, Y. (2001). Pernyataan Visi dan Misi Perguruan Tinggi. Mimbar, 17(1), 90-103. Diakses dari http://www.jpkk.edu.my/jpkk/index.php/maklumat-kami/visi-dan-misi.html

Hendrawan, I. (2020). Nilai-nilai Kepahlawanan Pangeran Sambernyawa pada Komunitas Supporter Passoepati di Surakarta. In Jurusan Sejarah, Fakultas IImu Sosial Universitas negeri Semarang (Vol. 2, Issue 1). Skripsi Jurusan Sejarah Universitas Negeri Semarang. Diakses dari http://jurnal.globalhealthscience group.com/index.php/JPPP/article/download/83/65\%0Ahttp://www.embase.com/search/result s?subaction=viewrecord\&from=export\&id=L603546864\%5Cnhttp://dx.doi.org/10.1155/2015/4 20723\%0Ahttp://link.springer.com/10.1007/978-3-319-76

Maulana, D. (2015). Peran Jaka Tingkir Dalam Merintis Kerajaan Pajang 1546-1586 M [Universitas Islam Negeri Syarif Hidayatullah]. Diakses dari http://repository.uinjkt.ac.id/dspace/bitstream/123456789/28866/3/DEDEMAULANA-FAH.pdf

Muthi"ah, U. (2019). Kebijakan Ekonomi Budaya Sultan Hadiwijaya Kerajaan Pajang (1546-1582). Yogyakarta: Universitas Islam Sunan Kalijaga.

Noname. (2021). Raden Mas Garendi (Sunan Kuning). Unkris. Diakses dari http://p2k.unkris.ac.id/id3/1-3065-2962/Sunan-Kuning_93917_p2k-unkris.html

Pratiwi, Anita Dian Joebagyo, Hermanu Yunianto, T. (2019). LEGIUN MANGKUNEGARAN TAHUN $1916 \pm 1942$ DAN IMPLEMENTASINYA DALAM PEMBELAJARAN SEJARAH1 (Skripsi). Tersedia dari FKIP UNS.

Saidang, S., \& Suparman, S. (2019). Pola Pembentukan Solidaritas Sosial dalam Kelompok Sosial Antara Pelajar. Edumaspul: Jurnal Pendidikan, 3(2), 122-126. https://doi.org/10.33487/edumaspul.v3i2.140. 